\title{
Avaliação da infiltração marginal de quatro seladores provisórios após a utilização de substâncias químicas auxiliares da instrumentação endodôntica
}

\author{
Evaluation of marginal leakage of four temporary materials after using irrigating solutions
} in endodontic treatment

Erica dos Santos Carvalho', Maria de Fátima Gesteira Malvar², Sílvio José Albergaria ${ }^{3}$

\section{Resumo}

O selamento coronário, juntamente com a obturação do canal radicular, possibilita um ambiente propício ao reparo dos tecidos periapicais, epílogo do tratamento endodôntico. Além disso, um bom selamento temporário impede que haja recontaminação entre as possíveis sessões do tratamento endodôntico, resguardando também a medicação intracanal. Muitos estudos têm sido realizados para investigar o vedamento marginal das restaurações temporárias. Este trabalho se propõe a avaliar a infiltração marginal na porção coronária de dentes que sofreram ação das substâncias químicas usadas no tratamento endodôntico, selados com quatro diferentes materiais provisórios. Para tanto, foram utilizados 60 pré-molares humanos hígidos, divididos em 5 grupos experimentais, conforme o material selador provisório empregado (Bioplic, Coltosol, XTempLC, IRM, Coltosol + Ação das substâncias químicas), e 2 grupos-controle. Os resultados obtidos indicaram que todos os materiais restauradores temporários avaliados permitiram certo grau de infiltração, sendo o Grupo II (Coltosol) aquele que apresentou o menor índice. Constatou-se também que as substâncias químicas auxiliares empregadas durante o preparo químico mecânico podem influenciar no selamento marginal, aspecto observado no Grupo V que apresentou infiltração coronária estatisticamente mais significante.

Palavras-chave: Endodontia, Restauração dentária temporária, Infiltração dentária.

\section{Abstract}

The coronary sealing, next to root canal obturation, permits an appropriate environment to the periapical tissues repair, which is the major endodontic treatment's outcome. Furthermore, good temporary sealing prevents new contamination between sessions of the endodontic treatment, also protecting the intracanal dressing. Many studies have been achieved for examining the marginal sealing of temporary restorations. This study intended to evaluate the marginal leakage in the coronary portion of teeth which suffered action of irrigating solutions used in endodontics, sealed with four different temporary materials. Sixty entire human premolars were divided into 5 experimental and 2 control groups according to each temporary restorative material used (Bioplic, Coltosol, XTempLC, IRM, Coltosol + instrumentation). The results indicated that all temporary materials used allowed a certain degree of infiltration, however, Group II (Coltosol) showed the least index. It was also observed that irrigating solutions used during biomechanical preparation can influence the marginal sealing, such as that observed in Group V which presented the greatest significant marginal leakage.

Keywords: Endodontics, Temporary dental restoration, Dental leakage.
${ }^{1}$ Especialista em Endodontia.

${ }^{2}$ Professora-Adjunta, Mestre em Clínica Odontológica pela Faculdade de Odontologia da UFBA.

${ }^{3}$ Professor Titular, Livre Docente em Endodontia pela Faculdade de Odontologia da UFBA.

Correspondência: Erica dos Santos Carvalho

Endereço: Av. Antônio Carlos Magalhães, 2501 - Ed. Profissional Center, sala

1204, CEP 40276-200 - Brotas - Salvador - Bahia

Fone: 7733595410

E-mail: erica_carvalho@msn.com

\section{Introdução}

O selamento coronário, juntamente com a obturação do canal radicular, possibilita um ambiente propício ao reparo dos tecidos periapicais, epílogo do tratamento endodôntico.

Nem sempre o tratamento endodôntico pode ser concluído em uma única sessão. Em casos de necrose e infecções do canal radicular, torna-se imperioso o emprego de uma medicação antimicrobiana intracanal. Se não for utilizado um bom material selador provisório, o sistema de canais permanece vulnerável à contaminação, alterando o efeito do curativo de demora, comprometendo assim o sucesso do tratamento endodôntico (SALAZAR-SILVA; PEREIRA; RAMALHO, 2004).

Da mesma forma, vale salientar cada vez mais a importância do selamento coronário mesmo após a obturação do canal, quando não for possível restaurá-lo definitivamente na mesma sessão.

Existe uma grande variedade de materiais restauradores provisórios disponíveis no mercado. Muitos estudos têm sido desenvolvidos com diferentes metodologias para avaliar a capacidade de selamento marginal destes materiais. Dentre os métodos mais utilizados para identificar tal infiltração, estão os corantes, radioisótopos, penetração bacteriana, filtragem de fluidos, processos histoquímicos, mensuração de fendas marginais e nanoinfiltração.

Em decorrência do aparecimento de recentes materiais seladores coronários, justificam-se novos trabalhos de avaliação destes materiais, para que se possa utilizá-los com maior segurança. Outrossim, entende-se que as substâncias químicas auxiliares do preparo químico mecânico interferem na permeabilidade dentinária, e consequentemente, no selamento marginal.

Face ao exposto, o presente estudo tem como objetivo avaliar a infiltração marginal coronária em dentes que sofreram ação de substâncias químicas usadas no tratamento endodôntico, selados com diferentes materiais provisórios.

\section{Materiais e Métodos}

Foram selecionados 60 pré-molares humanos hígidos obtidos no arquivo de dentes da Disciplina de Endodontia da Faculdade de Odontologia da UFBA. O projeto de pesquisa foi aprovado pelo Comitê de Ética e Pesquisa da Universidade Federal da Bahia de acordo com o parecer ético no 21/08. Para uma devida hidratação, os dentes foram mantidos em soro fisiológico na estufa a $37^{\circ} \mathrm{C}$ por 7 dias. 
As cavidades de acesso foram executadas com uso de uma broca esférica diamantada nํ 1014 (KGSorensen), e a largura foi padronizada em $3 \mathrm{~mm}$, tanto no sentido mesio-distal quanto no sentido vestibulo-lingual.

Os dentes foram imersos em hipoclorito de sódio a $1 \%$ (Solução de Milton-Asfer) por 1 minuto, em seguida em solução de EDTA a 17\% trissódico pH 7.4 (Bioethica, Bahia, Brasil) por 1 minuto, retornando à solução de Milton por mais 1 minuto, promovendo desta forma a remoção da smear layer e a limpeza da cavidade de acesso.

Todos os espécimes foram secados com cânula de aspiração. Uma bolinha de algodão foi deixada na entrada dos canais de modo que os $2 \mathrm{~mm}$ coronários ficassem livres para receberem o material restaurador provisório selecionado.

As amostras foram divididas aleatoriamente em 5 grupos experimentais com 10 dentes em cada, e 2 grupos controles cada um com 5 dentes:

- Grupo I - Selamento coronário realizado com IRM (Dentsply), manipulado de acordo com as recomendações do fabricante;

- Grupo II - Selamento coronário realizado com Coltosol (Vigodent), um material que adquire presa com exposição à umidade e não requer manipulação;

- Grupo III - Selamento coronário realizado com Bioplic (Biodinâmica), um restaurador provisório fotopolimerizável, acondicionado em seringa de 4 gramas, que foi inserido na cavidade e polimerizado de acordo com instruções do fabricante;

- Grupo IV - Selamento coronário realizado com XTempLC (DFL), um material que também necessita de fotoativação, acondicionado em seringa de 5 gramas, cuja inserção e polimerização procedeu de acordo com as recomendações do fabricante;

- Grupo V - Foi simulado um preparo químico mecânico, utilizando Endo PTC+Solução de Milton por 30 minutos; irrigação com EDTA a 17\% ph 7.4 por 1 minuto; lavagem com Sol. Milton; irrigação final com detergente e em seguida realizou-se o selamento coronário com o Coltosol (Vigodent), da mesma forma que no grupo II;

- Grupo VI - As amostras foram seladas com Coltosol (Vigodent) e completamente impermeabilizadas (controle negativo);

- Grupo VII - As amostras não receberam nenhum tipo de selamento coronário e foram impermeabilizadas conforme os grupos experimentais (controle positivo).

Todas as amostras foram impermeabilizadas em toda a superfície do dente com adesivo epóxi (Scotch Mix 3M) e esmalte para unhas (Colorama) exceto $1 \mathrm{~mm}$ coronário. O grupo VI, o controle negativo, foi impermeabilizado em toda sua extensão.

Todos os grupos foram em seguida imersos em corante de azul de metileno 1\% (Bioethica - Bahia - Brasil) e mantidos em estufa à temperatura de $37^{\circ} \mathrm{C}$, por 7 dias. Após este período, foram lavados em água corrente por 24 horas e as impermeabilizações removidas manualmente, com espátula lecron.

As amostras foram então seccionadas de mesial para distal com disco de aço em baixa rotação e logo após utilizou-se cinzéis, dividindo a coroa, até que toda extensão selada pelos materiais temporários ficasse exposta.

Para avaliação foram utilizados os seguintes escores de acordo com o grau de infiltração do corante azul de metileno na interface dente - material restaurador provisório:

\# 0 - ausência de infiltração ou infiltrado apenas superficialmente

\# 1 - Infiltração até a metade da parede cavitária;
\# 2 - Infiltração em toda extensão da parede cavitária, chegando a atingir a bolinha de algodão.

Os resultados obtidos foram registrados por 2 examinadores devidamente calibrados e tratados estatisticamente.

\section{Resultados}

Empregou-se a correlação de Spearman para verificar o grau de concordância entre os 2 examinadores, o que demonstrou não haver diferença significante entre estes. Portanto, para análise estatística, utilizou-se apenas os valores do examinador sênior.

Em seguida, foram calculadas estatísticas descritivas dos escores das infiltrações, de acordo com os grupos de estudo (Tabela 1). Uma vez que a variável dependente (escore) foi mensurada em escala ordinal e foram realizadas comparações entre 5 grupos independentes, optou-se pelo uso da ANOVA de Kruskal-Walis, seguida da utilização do teste de Wilcoxon com ajuste de Bonferroni para os valores de $p$ na comparação múltipla entre os grupos (Tabela 2). A análise foi realizada no pacote estatístico $R$ versão 2.6.2, plataforma Windows.

Tabela 1. Estatísticas descritivas das distribuições dos escores das infiltrações de acordo com os grupos

\begin{tabular}{lcccccc}
\hline Grupos & Mín. & Máx. & Q25 & Md & Q75 & iiQ \\
\hline IRM & 0 & 2 & 0 & 1 & 1,75 & 1,75 \\
Coltosol & 0 & 1 & 0 & 0 & 0,75 & 0,75 \\
Bioplic & 0 & 2 & 0 & 0 & 1,5 & 1,5 \\
XTempLC & 1 & 2 & 1,25 & 2 & 2 & 0,75 \\
"Coltosol+EndoPTC" & 1 & 2 & 1,25 & 2 & 2 & 0,75 \\
\hline
\end{tabular}

Tabela 2. Valores de $p$ para as comparações múltiplas entre os grupos após ANOVA de Kruskal - Wallis $(p=0,0003)^{*}$

\begin{tabular}{lcccc}
\hline & IRM & Coltosol & Bioplic & XTempLC \\
\hline Coltosol & 1,0000 & - & - & - \\
Bioplic & 1,0000 & 1,0000 & - & - \\
XTempLC & 0,3568 & $0,0031^{*}$ & 0,1285 & - \\
"Coltosol+EndoPTC" & 0,3568 & $0,0031^{*}$ & 0,1285 & 1,0000 \\
\hline${ }^{*} p<0,05$ ou &
\end{tabular}

\section{Discussão}

Um dos principais fatores que contribuem para o insucesso do tratamento endodôntico é a persistência de micro-organismos, ou uma reinfecção do canal radicular. Por isso, torna-se condição imprescindível a manutenção da medicação intracanal antimicrobiana intacta com um bom selamento coronário temporário, bem como um bom vedamento coronário definitivo, impedindo a recontaminação dos sistemas de canais radiculares.

Muitos trabalhos deixam claro que a infiltração, via acesso coronário, em canais radiculares obturados pode permitir a contaminação do periápice e induzir o aparecimento de periapicopatias (MATTOS; PIMENTA JÚNIOR; MELO, 2003; ADIB et al., 2004; SALAZAR-SILVA et al., 2004; SIQUEIRA JÚNIOR et al., 2005; PEREIRA, 2006; NISHIYAMA, 2007). O que vale afirmar que tão importante quanto o selamento da região apical é o selamento coronário.

O fator tempo também deve ser levado em consideração, pois o insucesso endodôntico aumenta se restaurações temporárias permanecem na cavidade bucal por muito tempo. Desta forma, a 
imediata colocação da restauração definitiva depois de finalizado o tratamento endodôntico é de extrema importância (SIQUEIRA JÚNIOR, 1997; HELING et al., 2002). Foi possível observar através da metodologia empregada neste estudo, que todos os materiais testados apresentaram algum grau de infiltração no período de 7 dias, intervalo mais frequente entre as sessões endodônticas. Se os materiais seladores temporários fossem mantidos por mais tempo em contato com o corante, provavelmente os valores de infiltração seriam maiores do que os obtidos neste estudo.

Vários materiais seladores temporários têm sido usados, mas estudos relatam resultados contraditórios sobre a habilidade de selamento desses. Alguns apresentam maior resistência às forças mastigatórias, porém, com pouca capacidade seladora. Assim, pesquisas vêm avaliando a microinfiltração cervical, na procura de um material resistente que apresente capacidade de selamento.

Objetivou-se, no presente estudo, avaliar a infiltração marginal de diferentes materiais provisórios quando as cavidades de acesso sofreram ação das substâncias químicas utilizadas durante o tratamento endodôntico.

As substâncias químicas auxiliares da instrumentação utilizadas neste estudo foram o Hipoclorito de sódio, substância mais usada mundialmente; a associação alternada de EDTA + Hipoclorito de sódio, utilizada para remoção da camada residual formada durante o preparo do canal; e a sequência preconizada por Paiva e Antoniazzi (1988) creme Endo-PTC + Solução de Milton e lavagem final com detergente.

Para avaliação da infiltração, foi utilizado o corante Azul de Metileno $1 \%$. Os dentes permaneceram no corante por sete dias, pois este é o intervalo mais frequente entre as sessões endodônticas e permaneceram em estufa a $37^{\circ} \mathrm{C}$ para simular a temperatura corpórea humana média. Pôde-se observar que a maioria das pesquisas empregou o método de infiltração de corante azul de metileno para a avaliação do selamento marginal (GEKELMAN et al., 1999; CRUZ et al., 2002; MATTOS; PIMENTA JÚNIOR; MELO, 2003; GOMES-FILHO et al., 2004; MARQUES et al., 2005; PEREIRA, 2006; FACHIN, 2007). Esta técnica in vitro permite mensuração quantitativa da infiltração e da interface dente-restauração, pois apresenta manchas bem definidas, favorecendo a interpretação além de fácil obtenção, de baixo custo.

Os resultados deste trabalho demonstraram que nenhum material estudado foi capaz de impedir totalmente a infiltração marginal, embora evidenciando uma diferença estatística significante entre os mesmos $(p<0.05)$.

O IRM (grupo I), apresentou infiltração, às vezes com escore 2, contudo, não apresentando diferença estatística com os grupos II, III, IV. Embora este material não tenha apresentado o melhor selamento, alguns autores sugerem que é indiscutível a resistência deste material aos esforços mastigatórios, motivo pelo qual foi recomendado em cavidades extensas, ou como selamento duplo após a inserção de uma camada de selamento provisório a base de óxido de zinco e sulfato de cálcio, tais como Cimpat, Coltosol, Cavit (POLO et al., 1996; HELING et al., 2002; CORTEZ et al., 2003; SALAZAR-SILVA et al., 2004; SILVEIRA et al., 2005). De acordo com Nishiyama (2007), os altos valores de infiltrações encontrados em espécimes restaurados com IRM podem ser devido ao seu preparo (mistura pó + líquido), sendo encontradas após análise pela MEV, presença de bolhas e espaços vazios entre o cimento e a dentina.

O Coltosol (grupo II), apresentou a menor média de infiltração, resultado semelhante ao encontrado por Marques (2005). Os materiais prontos para uso reduzem a variável de manipulação, pois tomam presa por hidratação e possuem alto grau de expansão linear, resultado da absorção de água, o que foi verificado por Silveira, Nunes e Silveira (2005).

O Bioplic (grupo III) apresentou resultados semelhantes, ligeiramente inferiores ao Coltosol (grupo II), mas sem diferença estatisticamente significante. Na avaliação in vitro de Fachin, Peron- di e Grecca (2007), o Bioplic apresentou-se como uma boa opção de selamento, visto que apresentou os melhores resultados nas amostras testadas. Tal desempenho pode estar relacionado principalmente à quantidade de partículas de carga inorgânica existente na sua composição química e à viscosidade em que é apresentado.

Quanto ao XTempLC (grupo IV), mostrou em todas as amostras algum grau de infiltração, sendo que em sete delas o corante penetrou até a bolinha de algodão colocada na câmara pulpar (escore 2). Esses resultados não apresentaram diferença significante com os grupos I, III e V, contudo, o grupo II mostrou-se melhor com diferença marcante $(p=0,0031)$.

No grupo $\mathrm{V}$, também foi utilizado o Coltosol, contudo, a cavidade foi tratada com uma substância cremosa (Endo-PTC) neutralizada pelo Hipoclorito de Sódio e lavagem final com detergente. Os resultados demonstraram uma influência destas substâncias no selamento marginal, uma vez que apresentou maior infiltração com diferença estatisticamente significante quando comparado com o grupo II que utilizou o mesmo Coltosol sem a utilização dessa associação $(p=0,0031)$.

Os grupos controles (VI e VII) foram utilizados para se confirmar a efetividade da impermeabilização, o que realmente foi comprovado, uma vez que não houve nenhuma infiltração coronária do corante no controle negativo (grupo VI).

A irrigação com EDTA 17\% melhora a adaptação e/ou adesão dos materiais às paredes dentinárias, da mesma forma que o hipoclorito de sódio associado ao Endo PTC também podem ter algum tipo de interferência no selamento (PEREIRA, 2006; VASSILADIS et al., 1996). Comparando-se o grupo V com o grupo II desta pesquisa, observa-se que ambos foram selados com o mesmo material, - Coltosol. Entretanto, o grupo V apresentou infiltração estatisticamente significante maior do que o grupo II, já que foi simulado um preparo químico mecânico irrigando com substâncias químicas que comprovadamente aumentam a permeabilidade dentinária.

A maioria dos trabalhos que avaliam a infiltração marginal, de materiais restauradores provisórios não considera o uso das substâncias químicas auxiliares do preparo químico mecânico empregadas na terapia endodôntica. Ao se considerar o emprego das referidas substâncias e comparar com os trabalhos já realizados com os aludidos materiais, constata-se que os resultados se alteram de forma significativa na endodontia. Novos trabalhos nesta mesma linha serão necessários, a fim de se encontrar, nestas condições, o melhor selador temporário endodôntico.

\section{Conclusão}

Nas condições experimentais em que esta pesquisa foi conduzida e com base na análise estatística, pode-se concluir que:

- Nenhum dos materiais restauradores temporários testados neste estudo foi capaz de impedir completamente a infiltração marginal em todos os espécimes.

- Os restauradores temporários Coltosol, Bioplic e IRM apresentaram valores de infiltração marginal estatisticamente semelhantes entre si. O XTempLC, entretanto, apresentou maior infiltração do que o Coltosol, mas não diferiu estatisticamente dos outros aludidos.

- $\quad$ O uso do hipoclorito de sódio a $1 \%$ associado ao endo PTC e irrigação final com solução detergente, simulando um preparo químico mecânico influenciou no selamento marginal de seladores temporários. Isto foi verificado porque o grupo $\mathrm{V}$ permitiu maior infiltração do que todos os outros grupos citados. 


\section{Referências}

ADIB, V. et al. Cultivable Microbial Flora Associated with Persistent Periapical Disease e Coronal Leakage After Root Canal Treatment: A Preliminary Study. Int. Endod. J., London, v. 37, n. 8, p. 542-551, Aug. 2004.

CORTEZ, D. G. N. Estudo In Vitro do Selamento Coronário Proporcionado por Diferentes Restaurações Provisórias. Pesq. Odontol. Bras., São Paulo, v. 17, n. 2, p. 167, ago. 2003.

CRUZ, E. V. et al. A Laboratory Study of Coronal Microleakage Using Four Temporary Restorative Materials. Int. Endod. J., Oxford, v. 35, n. 4, p. 315-320, Apr. 2002.

FACHIN, E. V. F.; PERONDI, M.; GRECCA, F. S. Comparação da Capacidade de Selamento de Diferentes Materiais Restauradores Provisórios. RPG Rev. Pós-Grad., São Paulo, v. 13, n. 4, p. 292-298, 2007.

GEKELMAN, D. et al. Microleakage of Four Temporary Endodontic Sealings After Thermocycling. ECLER Endod., São Paulo, v. 1, n. 1, Jan./Apr. 1999.

GOMES-FILHO, J. E. et al. Influência do Material Impermeabilizante Radicular na Infiltração Marginal com Azul de Metileno. Rev. Odontol. Araçatuba, Araçatuba, v. 25, n. 1, p. 28-32, jan./jul. 2004.

HELING, H. et al. Endodontic Failure Caused by Inadequate Restorative Procedures: Review and Treatment Recommendations. J. Prosthet. Dent., St. Louis, v. 87, n. 6, p. 674-678, June 2002.

MARQUES, M. C. O. A. et al. Avaliação da Infiltração Marginal em Materiais Restauradores Temporários: Um Estudo In Vitro. Pesq. Bras. Odontoped. Clin. Integr., João Pessoa, v. 5, n. 1, p. 47-52, jan./abr. 2005.

MATTOS, N. H. R.; PIMENTA JUNIOR, A. C.; MELO, L. L. Análise da Infiltração Coronária em Três Tipos de Restauradores Provisórios de Uso em Endodontia. J. Bras. Endod., Curitiba, v. 4, n. 13, p. 153-158, abr./jun. 2003.

NISHIYAMA, C. M. A. Avaliação In Vitro da Capacidade de Selamento Coronário de Três Materiais Usados como Barreira Adicional, em Dentes Tratados Endodonticamente, Obturados com Diferentes Cimentos Endodônticos, Utilizando o Método de Filtração de Fluido. 2007. 104p. Dissertação (Mestrado em Odontologia) - Faculdade de Odontologia. Universidade de São Paulo, Bauru, 2007.

PAIVA, J. G.; ANTONIAZZI, J. H. Endodontia: Bases para a Prática Clínica. $2^{\underline{a}}$ ed. São Paulo: Artes Médicas, 1988. 886p.

PEREIRA, K. M. M. Análise In Vitro do Selamento Coronário em Restaurações Provisórios e da Permeabilidade Dentária após Tratamento Endodôntico. 2006. 82f. Dissertação (Mestrado em Odontologia) - Faculdade de Odontologia, Universidade Federal do Pará, Belém, 2006.

POLO, I. et al. Selamento Marginal Cervical Simples e Duplo em Endodontia. Rev. Assoc. Paul. Cir. Dent., São Paulo, v. 50, n. 5, p. 435-439, set./out.1996.

SALAZAR-SILVA, J. R.; PEREIRA, R. C. S.; RAMALHO, L. M. P. Importância do Selamento Provisório no Sucesso do Tratamento Endodôntico. Pesq. Bras. Odontoped. Clin. Integr., João Pessoa, v. 4, n. 2, p. 143-149, maio/ago. 2004.
SILVEIRA, G. A. B.; NUNES, E.; SILVEIRA, F. F. Infiltração Marginal de Dois Seladores Provisórios em Diferentes Tempos. Arq. Odontol., Belo Horizonte, v. 41, n. 2, p. 105-192, abr./jun.2005.

SIQUEIRA JÚNIOR, J. F. Tratamento das Infecções Endodônticas. Rio de Janeiro: MEDSI, 1997. [196p].

SIQUEIRA JÚNIOR, J. F. et al. Periradicular Status Related to the Quality of Coronal Restorations and Root Canal Fillings in a Brazilian Population. Oral Surg. Oral Med. Oral Pathol. Oral Radiol. Endod., St. Louis, v. 100, n. 3, p. 369-374, Sept. 2005.

VASSILADIS, L. et al. Effect of Smear Layer on Coronal Microleakage. Oral Surg. Oral Med. Oral Pathol. Oral Radiol. Endod., St. Louis, v. 82, n. 3, p. 315-20, Sept. 1996. 